\title{
INOVANDO A ASSISTÊNCIA DE ENFERMAGEM AO BINÔMIO MÃE-FILHO EM ALOJAMENTO CONJUNTO NEONATAL ATRAVÉS DA CRIAÇÃO DE UM JOGO EDUCATIVO*
}

\author{
Luciana Mara Monti Fonseca** \\ Carmen Gracinda Silvan Scochi***
}

A criatividade é o casamento da arte e da ciência na enfermagem; é a síntese verdadeira da ciência, arte, teoria e práticas, cujos resultados em todas as enfermeiras são o pensar e o agir (FAWCETT et al., 1997).

Em diferentes partes do mundo, o cuidar de pessoas tem inspirado desde adequações de outros produtos existentes, passando pela improvisação de alguns outros, até a resposta mais efetiva de intencionalmente projetar e desenvolver produtos de interesse para a vida e para a saúde. Esse aspecto da enfermagem é tão interessante que se manifesta, tanto em países ditos de primeiro mundo como nos rotulados terceiro-mundistas (DIAS et al., 1996).

Nesta perspectiva é que nos sentimos estimuladas em desenvolver estratégias criativas na educação em saúde de puérperas atendidas em uma maternidade filantrópica do município de Ribeirão Preto-SP, a qual é campo de estágio de alunos de graduação em enfermagem e constitui local onde os docentes da Escola de Enfermagem de Ribeirão Preto da Universidade de São Paulo (EERP-USP), desenvolvem atividades de extensão de serviços à comunidade.

Vislumbrando a possibilidade de construir com a mãe, conhecimentos acerca dos cuidados com recémnascido e o aleitamento materno, num esforço para o preparo mais adequado da alta hospitalar, elaboramos um jogo educativo para instrumentalizar nossa prática educativa em alojamento conjunto neonatal, o qual denominamos "Ensinando puérperas sobre o aleitamento materno e cuidados com recém-nascido jogo educativo".

Colaboraram no desenvolvimento do projeto a Profa. Dra. Maria das Graças Carvalho Ferriani, docente do Departamento de Enfermagem Materno-Infantil e Saúde Pública, Cláudia Elizângela Fernandez Bis e Sueli Olívia Andreo Serra, enfermeiras mestrandas do Programa de Pós-Graduação - Área Enfermagem em Saúde Pública, da EERP-USP.

Pretendemos aqui divulgar essa invenção enquanto instrumento para uso em atividades de educação em saúde.

\section{O JOGO EDUCATIVO - ESTRUTURA E DINÂMICA}

A elaboração desse material didáticopedagógico inovador visou facilitar e dinamizar o processo ensino-aprendizagem junto à puérperas, idealizado a partir da necessidade de passar informações de forma dinâmica, com a participação efetiva delas na construção de seus conhecimentos.

O jogo educativo traz à discussão temas relacionados à amamentação como cuidados com as mamas, traumas mamilares e direitos da mãe que trabalha, bem como conteúdos relativos aos cuidados com o recém-nascido como curativo do coto umbilical, higiene corporal, banho de sol, vestuário, teste do pezinho, cólica e choro. As questões que direcionam a atividade lúdico-pedagógica abordam sobre essas

\footnotetext{
* Jogo educativo apresentado na Mostra de Produtos e Processos Inventivos de Enfermagem do $51^{\circ}$ Congresso Brasileiro de Enfermagem e $10^{\circ}$ Congreso Panamericano de Enfermería, Florianópolis - SC, 1999

** Enfermeira, mestranda do Programa de Pós-Graduação - Área Enfermagem em Saúde Pública, da Escola de Enfermagem de Ribeirão Preto da Universidade de São Paulo. Inventora do jogo educativo

*** Professor Doutor do Departamento de Enfermagem Materno-Infantil e Saúde Pública da Escola de Enfermagem de Ribeirão Preto da Universidade de São Paulo. Orientadora e colaboradora do invento
} 
temáticas de maneira mais diretiva ou indiretamente ao conterem afirmações ou questionamentos sobre alguns mitos presentes no cuidado do bebê.

O jogo apresenta tecnologia simplificada, artesanal, manufatura barata e acessível, sendo constituído de: um tabuleiro colorido com percurso figurado de 26 caselas, tendo ponto de saída e chegada dos jogadores; 50 cartas contendo perguntas sobre as temáticas citadas e, no verso, as respectivas respostas; dois dados e marcadores (peões) coloridos representando cada jogador ou dupla.

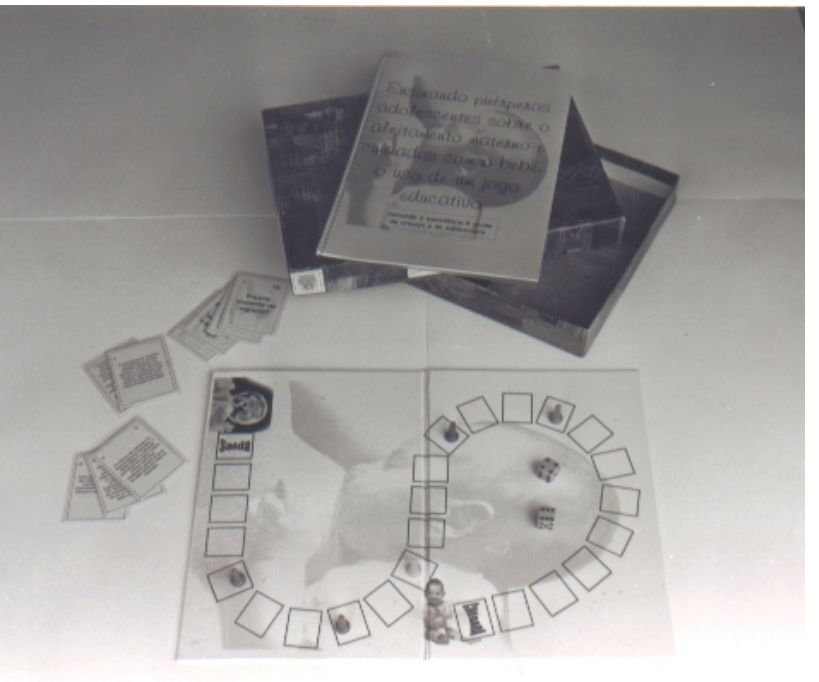

\section{JOGO EDUCATIVO}

O número mínimo de jogadores é 4 e o máximo 12 , formando-se duplas caso o número de jogadores seja superior a 5 .

$\mathrm{Na}$ dinâmica, cada participante ou dupla retira uma carta e se acertar a questão, caminha no tabuleiro o número de casas correspondente à soma de pontos obtida no lançamento dos dados. Ganha o jogo aquela(s) que chegar(em) primeiro ao final do percurso. Estimula-se participação de outras mães para completar as respostas às questões formuladas, esperando garantir, além da troca de experiências, que a resolução dos problemas apresentados saiam do próprio grupo, ficando mais próximo da realidade concreta delas.

Segundo MILET \& MARCONI (1992), o profissional da saúde deve orientar e facilitar o processo de ensino-aprendizagem, de maneira a promover as condições ideais para que os resultados ocorram através de conhecimentos sobre a linguagem utilizada no trabalho em grupo, nos vínculos que aí estabelecem, bem como no estímulo de seus integrantes. Dentro da dinâmica de trabalho em grupo desenvolvem-se ações educativas e através de materiais educativos pode-se demonstrar o esforço de todo o grupo, no sentido de explorar, decifrar, registrar, confrontar seus sentimentos, pensamentos e capacidade de realizações no atendimento das necessidades dos participantes.
Para ANTUNES (1999), durante muito tempo confundiu-se "ensinar" com "transmitir" e, nesse contexto, o indivíduo que aprendia era um agente passivo da aprendizagem e o que ensinava, um transmissor não necessariamente presente nas necessidades do aprendiz. Acreditava-se que toda aprendizagem ocorria pela repetição e que os que não aprendiam eram responsáveis por essa deficiência. Atualmente, sabe-se que não existe ensino sem que ocorra a aprendizagem, e que esta não acontece senão pela transformação, pela ação facilitadora do ensinador e pelo processo de busca do conhecimento, que deve sempre partir do aprendiz.

A idéia de um ensino despertado pelo interesse do aprendiz acabou transformando o sentido do que se entende por material pedagógico e cada aprendiz, independente de sua idade, passou a ser um desafio à competência do ensinador. Seu interesse passou a ser a força que comanda o processo da aprendizagem, suas experiências e descobertas, o motor de seu progresso e o ensinador um gerador de situações estimuladoras e eficazes. É nesse contexto que o jogo ganha espaço enquanto ferramenta ideal da aprendizagem, na medida em que propõe estímulo ao interesse do aprendiz. O jogo ajuda-o a construir suas novas descobertas, desenvolve e enriquece sua personalidade e simboliza um instrumento pedagógico que leva ao ensinador a condição de condutor, estimulador e avaliador da aprendizagem.

Para MACEDO (1995), os jogos educativos, de um ponto de vista estrutural, têm importância capital para a produção do conhecimento. O sentido e a necessidade de teoria (do esforço humano de explicar as coisas, de dar respostas ainda que provisórias para as perguntas que nos faz o jogo da vida) formulam-se e ganham contexto nos jogos. Em outras palavras, as fantasias, as mitificações, os modos deformantes de pensar ou inventar a realidade são como um prelúdio para futuras teorizações. Em síntese, os jogos são a base para o como e o porque das coisas.

Da análise das opiniões de um grupo de puérperas que vivenciaram a atividade educativa utilizando o jogo desenvolvido, verificamos que o mesmo constituiu em distração para as mães facilitando o aprendizado e que a dinâmica possibilitou a expressão de dúvidas deixando-as mais atentas no processo de educação em saúde (FONSECA et al., 1999).

Esperamos com o invento contribuir para a organização da prática de enfermagem em alojamento conjunto, através da utilização de tecnologia simplificada em atividades educativas, rumo ao processo de construção de uma assistência integral mais criativa e participativa, suscitando nos enfermeiros o desejo de ousar e criar. 


\section{REFERÊNCIAS BIBLIOGRÁFICAS}

01. ANTUNES, C. Jogos para a estimulação das múltiplas inteligências. Petrópolis: Vozes, 1999.

02. DIAS, L.P.M. et al. Potencial, talento e expressão artística: a enfermagem verbo criar. Texto Contexto Enferm., v. 5, n. 1, p. 46-63, 1996.

03. FAWCETT, J. et al. Commentary about Levine's on creativity in nursing. J.Nurs. Scholarship, v. 29, n. 3, p. 218-219, 1997.
04. FONSECA, L.M.M.; SCOCHI, C.G.S.; BIS, C.E.F.; SERRA, S.O.A. Utilizando a criatividade na educação em saúde em alojamento conjunto neonatal: opinião de puérperas sobre o uso de um jogo educativo. In: CONGRESSO BRASILEIRO DE ENFERMAGEM, $51^{\circ} \mathrm{e}$ Congreso Panamericano de Enfermería, $10^{\circ}$. Resumos dos trabalhos de tema livre. Florianópolis, 1999. p. 571.

05. MACEDO, L. Os jogos e sua importância na escola. Cad. Pesq., n. 93, p. 5-10, 1995.

06. MILET, M.E.; MARCONI, R. Metodologia participativa na criação de material educativo com adolescentes. Salvador: Paulo Dourado, 1992. 